\title{
Understanding Women's Experience in Graduate Mathematics Through a Focused Identity Lens
}

\author{
Lynn Liao Hodge $^{1} \&$ Lauren Wagener Riva ${ }^{2}$ \\ ${ }^{1}$ The University of Tennessee, Knoxville, USA \\ ${ }^{2}$ Berkshire School, Sheffield, USA \\ Correspondence: Lynn Liao Hodge, TPTE, The University of Tennessee, Volunteer Blvd., Knoxville, TN 37996, \\ USA. Tel: 1-865-974-8778. \\ Received: May 5, 2018 \\ Accepted: May 28, 2018 \\ Online Published: June 23, 2018 \\ doi:10.5430/irhe.v3n2p112 \\ URL: https://doi.org/10.5430/irhe.v3n2p112
}

\begin{abstract}
Despite relatively equal proportions of boys and girls enrolled in STEM courses during grade school, women are significantly underrepresented in STEM degrees and occupations around the world (Hill, Corbett, and St. Rose, 2010). The field of mathematics reflects this trend. Our focus in this article is on three women graduate students in mathematics at a University in the Southeastern United States. In particular, we were interested in their identities that include their perspective on the graduate program. Specifically, we sought to understand the norms, expectations, and resources of the social situation in which their identities were developing. As will become apparent, the three students illustrate different identities as they participated in graduate school mathematics.
\end{abstract}

Keywords: equity, STEM, women and mathematics, STEM, identity

\section{Introduction}

1.1 Women, Graduate Mathematics, and Identity

Math is different from other programs. My husband is a philosophy grad student and that's a whole different ballgame. They have some stresses that we don't have - like they are re-evaluated each year and can lose their assistantship, regularly kick students out and bring in new ones. In some ways that's more intense, but the workload is not nearly what it is in mathematics. I think that is true in the discipline in general. Philosophy professors are more laid back and don't work as hard as the math professors... But people who go into philosophy are different than people who go into math.

-Ruby, Graduate Student in Mathematics

Ruby's comments convey differences in identity across majors and program areas, suggesting that there are "math people" and "philosophy people." Our focus in this analysis is to look within the broad label of mathematics people in order to understand the different identities that individuals construct and the concrete implications for program and coursework design at the graduate level.

Despite relatively equal proportions of boys and girls enrolled in STEM courses during grade school, women are significantly underrepresented in STEM degrees and occupations around the world (Hill, Corbett, and St. Rose, 2010). The field of mathematics reflects this trend with women comprising $43 \%$ of Undergraduate math majors, $38 \%$ of earned doctorates in mathematics, $21 \%$ of postdoctoral associates in mathematics, and $12 \%$ of tenured mathematics faculty at doctorate-granting universities (Charney, 2014). Studies have indicated an array of possible causes at work behind the statistics (Cadinu, Maass, Rosabianca, and Kiesner, 2005; Herzig 2004; Johnson and Green, 2000; Kellogg, 2001; Kurtz-Costes, Andrews, and Ülkü-Steiner, 2006; Wilson, 2012). Putting forth one explanation, Walkerdine (1989) raised the argument in Counting Girls Out that "girls' underachievement in mathematics during the 1980s was socially constructed rather than a problem "with girls." This social turn in mathematics education (Lerman, 2000) shifted attention to understanding how girls and women are positioned in mathematics and the aspects of the social situation that contribute to women's underrepresentation in STEM-related fields. Since that time a number of studies have indicated causes such as feelings of isolation in academic programs and experiences of pressure from others to be and to act as a woman should, which stereotypically does not align with grand narratives about participation in STEM (Cadinu et al. 2005; Herzig 2004; Johnson et al. 2000; Kellogg, 
2001; Kurtz-Costes et al. 2006; Wilson, 2012). In spite of this emphasis on learning mathematics as a social construction, research has looked little at the students' perspectives on graduate level mathematics (Ong, Wright, and Espinoza, 2011).

We take as our focus three women graduate students in mathematics at a University in the Southeastern United States. In particular, we were interested in their identities that include their perspective on the graduate program. Specifically, we sought to understand the norms, expectations, and resources of the social situation in which their identities were developing. As will become apparent, the three students illustrate different identities as they participated in graduate school mathematics. The perspective on learning mathematics as a social practice reflected in this analysis is not a new one. However, we argue that this perspective continues to be underutilized in gender research and has the potential to contribute to efforts that seek to increase the diversity of Science, Technology, Engineering, and Mathematics (STEM) fields of study and professions. Examining graduate mathematics through a more focused identity lens enables us to understand better individuals' views and their valuations of the norms and expectations of graduate programs in mathematics. This focus allows us to be attuned to how doing mathematics is defined through norms that define life in programs and the potential conflicts that students experience. The issue is then not the students' valuations alone, but the relationship between students' valuations and how competence and doing mathematics are defined in social settings such as coursework and programs. We build on this introductory discussion by explaining the ideas that form the basis of this analysis in the next sections.

\subsection{Women and STEM Education}

A number of ideas gleaned from research inform our analysis. In the following paragraphs, we provide background for the significance and design of our study. An exhaustive review of literature relating to gender and STEM education is beyond the scope of our paper. Therefore, we focus on the ideas most salient to our study.

A substantial body of work has addressed issues of gender in education. A subset of this scholarship has yielded substantial research that has explored the issue of why women choose not to participate in STEM fields and also why those who initially participate leave (Eccles, 1987; Seymour and Hewitt, 1997; Herzig, 2000, 2004). This work has spawned frameworks and explanations ranging from explorations into the culture of STEM departments to early intervention programs that foster students' early literacy experiences with mathematics and science. At the university level, scholars draw attention to aspects of the culture in mathematics departments and how they can leave certain women and students of color feeling isolated (Herzig, 2004; Wilson, 2003). Both Kellogg (2001) and Herzig (2004) describe how students also noted an air of competition among fellow students. In addition, Herzig draws attention to how students experience lack of support and encouragement from faculty and other students. Still other students describe feeling invisible within their mathematics department while seeking to be mentored (Herzig, 2004). Research has also shown that how mathematics is predominantly taught at the University level, with professor lectures comprised of demonstrations, may be a frustration for women and students of color. Participants in Herzig's study (2000) spoke to the need for experiencing better mathematics teaching while Wilson (2003) notes how the opportunity to ask questions in a safe environment is often absent from women graduate students' perspectives. Henrion (1997) provides ample evidence of the social nature of mathematical activity and then argues that the image of a mathematician as a loner serves as a filter to keep certain types of people, such as women, out of mathematics. From this overview related to STEM education and women at the graduate level, we now discuss perspectives on gender in education as it relates to our study.

\subsection{Gender as a Response}

Notably, Dweck (2008) describes how high achieving female students often exhibit "maladaptive" behavior by taking few risks and only responding to teacher questions if they know absolutely that their answer is correct. Boaler (2002) clarifies another perspective that takes into consideration the learning environment and considers at its focus the relationship between the individual and the context. In doing so, her work aligns with research that locates students' difficulties in the design of educational settings rather than a characteristic of individual students. From this perspective, Dweck's description of female students' maladaptive behavior would be reformulated as students' responses to their learning environment, including interactions with the teacher, other students, and available resources.

Continuing in this vein, the work of Holland and Eisenhart (1992) takes as its focus women's response to the academic setting in which they participate, and how they develop who they are as they participate in and negotiate their identities in given contexts, such as the university. In their study of women at two universities, Holland and Eisenhart (1992) investigate the "world of romance" in which students enter as they become undergraduate women. This figurative world of romance gives high status to women who date, are attractive to the opposite sex, and who 
regard achieving romance as an important goal that occupies a great deal of their time and energy. Holland and Eisenhart note that this world of romance is seemingly in conflict with the world of academic achievement. Further, women who strive to excel in coursework and intellectually are often devalued within this world of romance. Their analysis focuses as well on the women who successfully pursue their academic and intellectual interests as a priority, in spite of the conflicts that they experience operating within the world of romance. Significantly, Holland and Eisenhart found that women who were able to solidify and feel comfortable with who they are academically had a number of supports that included a group of peers who shared similar interests and goals and structural supports (e.g. faculty advisors) that were instrumental in affirming students' academic achievement. Of particular interest in this study is how the students developed ideas of what it means to be a college student as they participated in the activities that surround college life and as these collective experiences took on a unique kind of meaning to their individual lives. This sense making on the participants' part contributed to the identities they constructed as college women. In this study, we consider the identities that students develop as they participate in the practices that come to define life within a program and across coursework in order to make sense of women's experiences. Prior to elaborating on a specific identity framework, we first discuss our perspective on identity.

\subsection{Identity as Socially Constructed}

A number of studies in mathematics and science education have focused on the notion of identity (Boaler and Greeno, 2000; Cobb and Hodge, 2002; Gutstein, 2002; Martin, 2000; Sfard and Prusak, 2002). Although these studies seem to conceptualize identity in a number of ways, they collectively emphasize the potential usefulness of identity in addressing timely issues including students' motivation and sense of affiliation in learning science, engineering, and mathematics. Because of these different conceptualizations of identity, it is important to define how identity will be used in this article. We draw from Lave and Wenger as we take a socially situated perspective on identity and view identity as grounded in the concrete relations and mutual engagement of communities such as the mathematics classroom and a mathematics department. From this perspective, students become substantial members of a mathematics classroom community as they learn the normative ways of thinking and acting that have been established within that particular community. Much of this learning is implicit and involves unarticulated suppositions and assumptions as well as particular ways of speaking and using particular tools and other resources. In addition to these ways of knowing, this learning also involves students' development of a sense of who they are within this community, their place and position within this classroom. Students learn mathematical ideas and develop certain competencies and at the same time they learn what it means to be a mathematics student in a particular classroom. In participating in the practices of a mathematics class, students become particular kinds of mathematics learners. Students' mathematical identities reflect particular orientations toward learning mathematics, place a certain value on mathematics, and view mathematics in particular ways. In this case, these identities involve the extent to which students develop a sense of affiliation with graduate mathematics as it becomes realized through their coursework.

\subsection{An Identity Framework}

Identity from this situated perspective is mutually constituted by the community and the individual. Students develop a response or construct an identity as they play a part in the relations of engagement that come to define a community. Students negotiate identities as they participate and contribute to the emergence of social practices such as doing mathematics in graduate school. We draw on an interpretive framework of identity that includes three dimensions (Cobb, Gresalfi, \& Hodge, 2009). These include math identity or core identity, normative identity, and personal identity.

\subsubsection{Mathematics Identity (or Core Identity)}

In using the construct of mathematics identity, we refer to the more enduring relationship that students' have with mathematics and their reasons for engaging with the discipline. Both competence and personal identity refer to more specific situations of mathematical learning. We describe both of these constructs in further detail. We draw on Gee's (2000) term of core identity in this case.

\subsubsection{Normative Identity}

We view the classroom and the department as spaces in which resources interact to provide certain kinds of opportunities for students (Cohen and Lotan, 1995; Engle and Conant, 2002; McDermott, Goldman, and Varenne, 2006). This view of classes and programs shifts the focus from students to students' interaction with various aspects of the social context. Difficulties that are typically viewed as deficiencies to be remediated in students are deemed as constructions that arise from the interaction among individuals, resources, and the arrangement of the department 
context. Opportunities are presented in this context and involve situations in which students can display their competence. Mathematical competence is seen as constructed by and through different resources. Therefore, what counts as mathematical competence differs from department to department. What becomes constructed as mathematical competence, the roles of the professor and students, and other features of classes and programs can be seen as contributing to students' developing relationships with graduate mathematics. This dimension then addresses what students must do and the practices in which they must engage in order to be successful in a given program or department.

\subsubsection{Personal Identity}

Originally, the construct of personal identity was used to analyze the identities that students develop in a middle school mathematics class (Cobb, Gresalfi, and Hodge, 2009). In this way, the focus of the analysis was on the students' views of the obligations and the practices that were normative in the mathematics classroom setting. For the purpose of our study, given that we are understanding students' experiences across coursework, concerning a graduate program, we view one aspect of personal identity as focused on the broader culture of the program that encompasses experiences across coursework and in informal spaces and interactions taking place outside of specific courses. Therefore, this construct has been adapted for the purposes of our analysis and requires some synthesis on the participants' part to consider their multiple experiences across different settings. This construct examines students' views of what it means to know and do mathematics in graduate classes and in graduate mathematics programs. In addition, personal identity documents students' valuations of certain practices that constitute life in mathematics departments and the extent of students' affiliation with learning mathematics. The third dimension this construct examines is students' views of competence within the program and an assessment of their own competence. In this analysis, we focus on the participants' personal identities followed by a discussion of how this particular lens can be useful to the design of coursework and programs.

\section{Method}

The analysis draws on data collected from three female participants in a pilot study for a larger research project on women mathematics graduate students. The three female participants were doctoral students at various stages in the mathematics department at a university in the Southeastern United States. All participants engaged in semi-structured, individual interviews with the two authors. Interviews were open enough to allow participants space to raise issues of their own that they deemed as significant to their experiences in K-12, undergraduate, and graduate mathematics. Each interview lasted approximately one hour.

\subsection{Data Analysis}

Data analysis procedures involved identifying and grouping segments related to the conjectured categories, and drawing on open coding (Strauss and Corbin, 1990) to develop possible themes that cut across interviews with individual students. The process of analyzing interview data involved multiple phases of coding. We analyzed the interviews by first transcribing the audiotapes and analyzing them student by student in order to identify an individual students' comments about their experiences in their graduate program, their previous schooling experiences, what it takes to be successful in their graduate program, and their valuations of the practices that they noted. This process involved analyzing the interview for one student, then examining another student's interviews, and so on and so forth.

After this initial stage, we looked across interviews for significant themes along the three dimensions of math identity, competence, and personal identity that were mentioned in the above paragraph. We developed a chart that summarized each student's comments concerning the identity framework in order to obtain a sense of students' relationships with graduate mathematics. We then included examples of students' comments that illustrated these ideas. In this manner, conjectures about the different identity dimensions were developed, tested, and revised as individual interviews were examined and relevant segments identified. The data were analyzed for significant differences and common themes in order to capture experiences in graduate mathematics more fully (Fine and Weiss, 1998).

\subsection{The Participants}

The three participants of the study are graduate students in mathematics at a university in the Southeast United States. All three began as doctoral students. Two, Casey and Ruby, at the time of the interviews, continued to be students in the doctoral program, with Casey at dissertation stage, and Ruby having recently passed comprehensive exams. A third participant, Jenny made the decision prior to the interview, to work toward completing her master of science in mathematics degree rather than continuing to complete a doctorate. Casey is a petite, Hispanic woman who enters 
into any discussion with an air of confidence. In a discussion about mathematics and mathematics education, she perceives herself as knowledgeable and assertively offers her opinions. Her excitement about having a one-year-old child is ever-present, as almost every conversation is connected to being a parent. She describes her decision to become a mathematics major as having to do with early childhood experiences and then later experiences at the University level. As she notes,

My family is very math and science oriented. All three of my siblings are civil engineers. So, I think when they saw that I was good at this, I don't know if it was the flash cards or whatever, they were like, "Oh. Let's bring it on." And I would ask for math flashcards all the time. Now, that is arithmetic in a sense, that's not necessarily math. But I found something that was fun. I wasn't always necessarily very good at it. In other words, I didn't always get A's, as weird as that is. When I was in high school, one of the reasons why my parents chose the town that they chose was that the public high school had a fantastic, well reputable math team...

Her decision to major in mathematics came after she had started at the University level. Casey decided to major in zoology initially. However, her grades in chemistry (e.g. A, B, and C) prompted her to rethink her major.

Casey: ... And, within the first month, I dropped Molecular Biology. So, I kind of went through like a semester of four "mathy" classes, and I got straight A's. I had this one professor, who I had scored a 100 on the final exam, and he like came up to me and gave me a hug. And he was like, "Why are you not a math major." And I just kept getting that question over and over again.

She further described how the decision to pursue a $\mathrm{Ph}$. D. in mathematics had to do with three reasons: First, her cousin's decision to pursue a $\mathrm{Ph}$. D., second, the experience of conducting an undergraduate research project under the supervision of a well-respected mathematics professor, and third, the joint decision made with her husband to continue their graduate studies and delay starting a family.

The next participant to whom we turn is Ruby who is a petite, Caucasian female student. Ruby is a native of the city, in which the university is located, and has a strong network of support from family and friends in the community. In casual conversation, Ruby appears timid and soft-spoken, but as she begins to discuss mathematics her passion and confidence become strikingly apparent. This passion is reflected in her comments about what brought her to the study of mathematics. As she remarks:

I thought I would study biology when I came to college. I was not encouraged to do math in K-12. I always did well in math, but I was in the regular (not the advanced) track. My first year here, I had a really nice Calculus course; it had proofs, and I really liked proofs - that's why I decided to study math, I just fell in love with proofs.

She goes on to note how her interest in mathematics was confirmed during her undergraduate years. As she describes:

I quit math for a year (junior) in undergrad and thought I would do something more person oriented. I came to math late in life and had some bad experiences at the end of my sophomore year. I studied French and went abroad, but I really missed math and had to come back. Since then, I haven't had any problem with motivation because I tried leaving math and really missed it.

Jenny is a Caucasian woman, who has decided to leave doctoral study in mathematics, changing to the Master's degree program option. She makes it clear that graduate school has really beaten her down and stripped her of her self-confidence, and these feelings are evident in her demeanor during the interview. In describing what brought her to doctoral studies in mathematics, she mentioned that her mother is a math professor at a small college. In her comments, she focused on her undergraduate university mathematics preparation. In particular, she remarked extensively about her lack of preparation, from her perspective, as reflected in the following comments:

I did the bare minimum math degree from a small, private liberal arts college because I was doing a double major in German and made room to take an entire semester off of math in my Junior year to go abroad... I could have pushed the department a lot harder to prepare me better than they did, but I didn't push.

In the next section, we will examine the participants' comments regarding their ideas about the mathematics program and what competence entails.

\section{Insights Gained}

A number of points emerged from the participants' comments about doing mathematics in graduate school. In this section, we highlight their comments while drawing attention to common themes, significant differences, and key 
resources from the participants' perspectives. In documenting their personal identities, we are seeking ideas that have the potential to inform program and instructional design. In one sense, all three of the participants can be considered successful students based on their timely completion of graduate program requirements. On one hand, their comments reflected differences in their ideas about their own success and competence within the doctoral program. On the other hand, they shared similar comments regarding the culture of the mathematics program, reflecting the themes of Working independently and Competition. We examine the participants' personal identities along the three dimensions of 1) Perceptions of the graduate mathematics program culture, 2) Perceptions of what competence in the graduate mathematics program entails, and 3) Perceptions of their own competence within the program. In addition, we explore participants' valuations of aspects of the program culture they bring out in their comments.

\subsection{Perceptions of the Program Culture}

\section{Working Independently}

All three of the participants commented on how their work within the program involved individual effort. For example, Casey makes the point that working independently is part of the "culture" of the department. And, yet, she indicates that this aspect of the culture, as conveyed by an advisor in particular, does not make sense.

Casey: My current advisor is not the best at helping you along because he really expects you to be independent. So, he's not a very good person to go to when I need help, shall we say. Which is kind of, you would think an advisor that's what they are supposed to do. But I think that it's just the culture, a little bit, of the math department. You're expected to do your work very independently and not collaborate with anybody.

Ruby's comments echo Carrie's remarks by further elaborating on how this independence may become concrete through interactions between students and faculty. Ruby comments:

Another thing is a lot of the professors won't help you with the homework problems... They think you should come to it on your own... For example, Dr. "Smith" won't help you with the homework; you can come in and talk to him and he'll just say, "That's interesting." You can tell him your ideas, and I tried doing that. But it wasn't very, he won't help you. And I don't know I think that's what homework should be about. And the other thing is if you help a student to work through a few homework problems. You know. We teach, and if you help a student to work through a few homework problems, then they kind of see how to do it. But he wouldn't do that.

Ruby's comments reflect the emphasis on independent work, particularly through one example of an interaction with a professor. She raises the idea that some prompts or help can be useful, based on her teaching experiences and should be part of the process of doing homework. A third participant, Jennifer, shares comments that also reflect this emphasis on solving problems individually. She further points to the helpfulness of gaining ideas from someone else. As she notes:

At our level, you don't need someone to just tell you the answer but a hint, a little push in the right direction. I'm totally stuck; I'm missing the point of this problem. Just nudge me in the right direction, and I'll go from there. I'll come back if I have more questions. My Algebra professor, from the 400-level class. I can get help on homework, but there was one day that I just didn't understand anything that had gone on in class. So, I went in and said, "I'm a little confused on the homework, but I was totally lost in class today. Can we just talk about that?" And he just kind of sat there and stared at me. And so, I realized that no I'm not going to get the lecture again. I'm not going to get his best effort at re-explaining it. I'm going to have to ask a few very specific questions, and I might get an answer to those. So, I tried a couple of questions, and I got a two- or three-word answer. And at that point, I was so confused that I just gave up.

In addition, Jenny had an opportunity to enroll in two mathematics education courses as part of the College of Education in the department of teacher education at the university. She further emphasized the culture of individual effort in her graduate mathematics program through a comparison between the mathematics and mathematics education courses in which she had participated.

Jenny: The thing that struck me about education classes were that it was so social - don't know if it was the students, class, or professor. In math, in contrast, I have my office 20 feet from these people. If I have class with people one semester and don't have class with them next semester, they may not remember my name.

Jenny's comments explain two different ways that the mathematics graduate program culture emphasizes the individual. There is a social aspect that includes interacting with others in a collegial manner. A second aspect 
involves the problem-solving endeavor as being highly individualistic. The comments of Carrie and Ruby conveyed this aspect of problem solving as an individual process. Taken collectively, one implied idea is that one should solve a problem on his/her own, and that this individual emphasis fosters learning of mathematics.

\section{Competition}

A second theme that emerged in the interviews was that of competition in the mathematics program. Two of the three participants noted this aspect of the program culture. Ruby identities as a sense of competitiveness among professors as well as graduate students. She comments:

Mathy feel is competitive. Seems like a lot of tension, even between professors. A lot of tension, and a lot people don't get along and don't like each other. People aren't as friendly. I think that all the graduate students get along; there's no one that I don't get along with. But even within graduate students, there is a competitive feeling.

Ruby goes on to point out that part of the competition has do to with how the students in the program are graded, relative to one another. As Ruby comments:

One thing that I don't like that I think makes the atmosphere so competitive is that often times they grade us based on how we do compared to everyone else. It's very common - maybe half of the classes I've taken are graded that way. So, you feel like no matter how much better you get, if everyone else is getting equally better, you're not getting any better. And part of the way they evaluate you is your grade.

Ruby's comments convey the general atmosphere of the mathematics department from a graduate student's perspective, highlighting the competitive nature of the program. She also goes on to explain a possible mechanism that contributes to the sense of competition among graduate students. Jenny's comments reflect this general feeling of competitiveness as well. She notes that one possible reason for this competitiveness is that this kind of culture is one that professors experienced during their graduate work.

Jenny: I think a lot of that may just be enculturation for the way it was done when they went through as graduate students, wherever that was. They're used to this competitive atmosphere. And sort of a tough, figure it out yourself, and help your classmates at peril to your own grade and blah, blah blah.

Although Ruby and Jenny shared comments about the competitive nature of the program culture, Carrie did not. Her comments, when asked about words that describe the mathematics graduate program, reflected a sense of being busy and flexible at the same time. This might be attributed to her situation at the time of the interview. She was the farthest along in the program, engaged in writing her dissertation. This might also speak to having a broad and deep social network in the department, as she described in her interviews. Casey had initiated and been actively involved in developing a mentoring program in the department during her time in the program. We can only speculate that the relationships she developed while working on the mentoring program may have provided a structure that alleviated any competitiveness that was typically experienced by students.

\subsection{Perceptions of Competence}

When asked about students who are successful in the program, all participants were able to respond quickly. Two responded with the names of specific students while a third participant described successful students more generally. Their comments indicate differences in how they regarded competence in the program. This is significant because their response to this question about competence gives us insight into how they are making sense of what practices, artifacts, and attitudes are valued in the program or at least communicated to them by the various components and individuals in the program. It is about understanding their perspective, but more so, it is about how they are making sense of what (and who) has clout within the program. For Ruby, her comments emphasize the importance of details, neatness, and being correct all the time. As she notes,

"Carl." I mean he's so perfect. He knows the answer to everything. And, I've had a lot of classes with him; he's a nice guy. He's very well organized and very neat. His proofs, every little, last detail is there; yet they're on time and correct. And things seem to come pretty easy to him. My first year of graduate school, that's the way it felt, like things were going by so fast. That whole summer, I just took those books and reread them because I just didn't feel like I had any of it down. But, he was ready for it coming in and so he's on top of it now.

Ruby also indicates that being ready when you first start is important. This is a theme that is echoed by the other two participants. Casey's comments focused on two students who had already completed their doctoral degrees and had assumed faculty positions at Masters-granting universities. As she points out: 
Okay. Okay. I can think of one. I can think of one. He graduated before I even came to the university "Matt." From my understanding, he had a good research agenda; he continues to publish really well in his field. He is there at all the local meetings; he's even started to organize his own meetings. He's on several boards of the professional societies, including education. He has a strong leaning in research on mathematics education. He loves teaching, but also continues to put out professionally. And he was married in graduate school, and now he has two kids. I would say that is a successful student. He left with his Ph.D. and accepted a tenure track position, no post-doc required, at a medium size, public university with a Master's program. So, I would say, in my mind, that makes him very successful.

Casey's comments emphasize that success is measured by what students do professionally and personally following completion of the program. She notes that Matt has assumed a tenure-track position with no post-doc required and in addition, he has two kids. Casey brings up another successful student.

I would have to say, if there's another one: "Alice." She graduated a couple years ago. She didn't go on right on to a job position, but I think her husband was finishing school. So, she stayed for a year to do a post-doc, and then, she accepted a good position elsewhere. I don't know that much about her professional activities. I never got the impression so much that she was involved in a lot, but that might just be because she was a little bit more applied math than I was; so, I just didn't see her at some of those things. So, I would say that those are two.

As both of her comments suggest, Carrie described success in the program based on the position students accepted once they graduated with their doctorate. Her comments seem to make sense given she was writing her dissertation at the time and anticipating the job search. For Jenny, success involved doing well in coursework and enjoying the program overall. As she comments:

But I think it's kind of how I see it. It's the ones not only who are not only doing well in classes but keeping up with requirements even ahead of the deadline, but seem to be enjoying what they are doing and not stressed to the point of breaking by what's going on, and participating in the department, willing to reach out and help somebody else because they're not just, "How am I going to get this done", freaking out about their own stuff. They've got time they can waste playing darts or helping a younger student with their homework or whatever.

The participants offered comments about competence that included general attributes and specific students as examples of mathematical prowess and as exemplars in terms of positions they accepted following graduation. Further, there were comments about successful students enjoying the program and having available time to do other things besides focusing on their own studies.

\subsection{Perceptions of Their Own Competence}

When asked about students who are successful in the program, all participants were able to respond quickly. Two responded with the names of specific students while a third participant described successful students more generally. Their comments indicate differences in how they regarded competence in the program. This is significant because their response to this question about competence gives us insight into how they are making sense of what practices, artifacts, and attitudes are valued in the program or at least communicated to them by the various components and individuals in the program. It is about understanding their perspective, but more so, it is about how they are making sense of what (and who) has clout within the program. For Ruby, her comments emphasize the importance of details, neatness, and being correct all the time. As she notes,

"Carl." I mean he's so perfect. He knows the answer to everything. And, I've had a lot of classes with him; he's a nice guy. He's very well organized and very neat. His proofs, every little, last detail is there; yet they're on time and correct. And things seem to come pretty easy to him. My first year of graduate school, that's the way it felt, like things were going by so fast. That whole summer, I just took those books and reread them because I just didn't feel like I had any of it down. But, he was ready for it coming in and so he's on top of it now.

Ruby also indicates that being ready when you first start is important. This is a theme that is echoed by the other two participants. Casey's comments focused on two students who had already completed their doctoral degrees and had assumed faculty positions at Masters-granting universities. As she points out:

Okay. Okay. I can think of one. I can think of one. He graduated before I even came to the university -

"Matt." From my understanding, he had a good research agenda; he continues to publish really well in his field. He is there at all the local meetings; he's even started to organize his own meetings. He's on several 
boards of the professional societies, including education. He has a strong leaning in research on mathematics education. He loves teaching, but also continues to put out professionally. And he was married in graduate school, and now he has two kids. I would say that is a successful student. He left with his Ph.D. and accepted a tenure track position, no post-doc required, at a medium size, public university with a Master's program. So, I would say, in my mind, that makes him very successful.

Casey's comments emphasize that success is measured by what students do professionally and personally following completion of the program. She notes that Matt has assumed a tenure-track position with no post-doc required and in addition, he has two kids. Casey brings up another successful student.

I would have to say, if there's another one: "Alice." She graduated a couple years ago. She didn't go on right on to a job position, but I think her husband was finishing school. So, she stayed for a year to do a post-doc, and then, she accepted a good position elsewhere. I don't know that much about her professional activities. I never got the impression so much that she was involved in a lot, but that might just be because she was a little bit more applied math than I was; so, I just didn't see her at some of those things. So, I would say that those are two.

As both of her comments suggest, Carrie described success in the program based on the position students accepted once they graduated with their doctorate. Her comments seem to make sense given she was writing her dissertation at the time and anticipating the job search. For Jenny, success involved doing well in coursework and enjoying the program overall. As she comments:

But I think it's kind of how I see it. It's the ones not only who are not only doing well in classes but keeping up with requirements even ahead of the deadline, but seem to be enjoying what they are doing and not stressed to the point of breaking by what's going on, and participating in the department, willing to reach out and help somebody else because they're not just, "How am I going to get this done", freaking out about their own stuff. They've got time they can waste playing darts or helping a younger student with their homework or whatever.

The participants offered comments about competence that included general attributes and specific students as examples of mathematical prowess and as exemplars in terms of positions they accepted following graduation. Further, there were comments about successful students enjoying the program and having available time to do other things besides focusing on their own studies.

\subsection{Resources}

All three of the participants included family, friends, and other graduate mathematics students as their primary resources. This is not unusual as graduate students who are successful in completing STEM degrees cite social networks, including family and friends as a key resource in their success (Espinoza, 2011). However, the data presented here shows the nuances involved, including the specific ways these social networks offer support. Two of the participants, Casey and Ruby, included their graduate advising professor as a resource. We begin with Jenny's comments which are illustrative of family and mathematics support:

Mom has a Ph.D. in math. So, aside from just being my mother and being great on that score, she got me through that Algebra course that I was lost in because her Ph.D. is in Algebra. So, I had a tutor that I could call when I was lost, scared, and desperate at 2:00 in the morning, and she'd get out of bed, rub the sleep out of her eyes, and try to talk to me about Algebra. Of course, both of my parents have been supporting me, adding money to the income I get from the department so I can afford a decent place to live. And they're just great. I talk to them on the phone a lot, and they're support for a lot of things.

Jenny's comments highlight the different ways her parents support her, through the math courses and emotionally. Ruby's comments reflected the helpfulness of working with other students during the first part of her doctorate work.

Working with other students. I kind of forgot that, since I finished prelims, I haven't been working that much with other student; I've not been taking that many classes. But that was really rewarding my first two years when I was taking those classes. I really enjoyed working with other students because I had never done that before as an undergraduate, and it was just so much fun and I learned so much talking with other people about math.

Casey emphasized the support of two professors as important to her positive doctoral studies experiences. For one, she highlights how this particular professor had funding for her to participate in research and attend a conference to present their findings. For a second professor, she draws attention to motivation. As Casey comments: 
I had another professor for my Mathematical Ecology prelim class. He's no longer here, but he just expected a really high standard. And he was just a very good professor and got us excited about the field. And I think that's really important to have enthusiasm. And he just made class fun, which in a math class is not always easy. I felt like doing well in his class it just made me feel really good about what I was doing about my career. And being successful in that class and being encouraged and him letting me know that I was being really successful in the class gave me a lot of confidence.

These participant comments reflect the different kinds of resources they viewed as valuable to their graduate studies in mathematics. All the resources had to do with other individuals and the different ways they provided support. This support took the form of encouragement, inspiration, a sense of belonging, and helping with the mathematical content itself.

\subsection{Summary}

In sum, as the participants' comments reflect, the graduate mathematics program, can be described primarily as working independently and somewhat in terms of being competitive. Importantly, all three participants viewed competence within the program in different ways including being correct and precise in solving mathematics problems presented in coursework, garnering a position as a university professor following program completion, and balancing doing well in coursework and enjoying the program. In spite of these different views of what competence entails, all three participants described some aspect of their graduate experience as a success. In terms of resources, the relationships with others were key to the participants. Developing a sense of belonging, feeling encouraged, and experiencing support in terms of the mathematics were points collectively made by the participants.

Provide dates defining the periods of recruitment and follow-up and the pnmary sources of the potential subjects, where appropriate. If these dates differ by group, provide the values for each group.

\section{Discussion and Conclusion}

In the concluding paragraphs of this article, we focus on the specific insights gained through the identity framework on which we have drawn and their implications for graduate studies in mathematics. The two aspects of the program culture reflected in the participants' comments related to working individually and the competitive nature of life in the mathematics department. All of the participants seemed to question the emphasis on individual problem solving, which has been reported in prior research (Ong, Wright, and Espinoza, 2011). Relatedly, both Burton (1999) and Henrion (1997) noted that collaboration is an important aspect of working as research mathematicians, but is not an aspect that is fostered in the culture of mathematics generally, but specifically at the graduate level. Making these research findings more concrete, the participants gave examples of meetings with professors that reified this notion of doing mathematics as solo work. There was also a sense of questioning this emphasis on problem solving as an individual endeavor. Two of the participants conveyed that the competitive feeling made the culture stressful and tense, in terms of professors and graduate students, whose grades were determined in comparison to one another in some courses. This finding has implications for designing tasks that are collaborative in nature for professors and instructors as part of professional development opportunities. These kinds of activities would support views of problem solving as creative work where collaboration can be critical (Cobb, 1999). Further, creating a supportive yet challenging environment that views assistance as a positive resource can also reduce some of the aspects of competitiveness that are part of the mathematics culture, as two of the participants described. Involving graduate students in outreach projects in schools and the community can also contribute to a more collaborative environment and a less competitive one. Overall, efforts, such as book studies that provide opportunities for discussions about what it means to learn mathematics, possibly involving faculty from different departments, including mathematics, psychology, and education would be valuable in challenging notions of individual problem solving as critical to fostering deep mathematical understanding. Providing structured time for students and faculty to build social networks in the department and across departments would alleviate the tensions associated with doing mathematics as a solo effort.

The participants' comments about competence within the program reflected that success is more than grades or completing requirements. Success, as reflected in their comments, is about enjoyment and about a sense of accomplishment. The participants showed differences in their views of success, but overall their assessments included aspects beyond grades only. For one, competence involved the type of position earned after graduation. For another, it was about perfection, and finally for another, it was about enjoying and doing well in coursework. These points concerning competence align with Bass (2003) who makes clear the difference between mathematics as a discipline and as a profession, argues that while mathematics doctoral programs in the United States provide strong disciplinary education in mathematics, they can improve in the area of preparing students for all aspects of work 
within the profession of mathematics. This would include teaching and working collaboratively. Our findings indicate a need for students to find support in terms of mathematics, but also in terms of their life circumstances. Some undergraduate university programs (e.g. honors programs in particular) offer students two different advisors who can offer support in terms of academic decisions and life aspects. The idea of two advisors, if feasible, might be a potential way to support students' success in these two areas that they view as valuable, and as contributing to their sense of satisfaction in the program.

In terms of resources, the participants pointed out a number of resources, primarily involving interactions with others that were helpful in their graduate studies.

These interactions involved working out the mathematics and finding encouragement, motivation, and inspiration while building a social network. Work from Walker (2006) found peer groups to be an important resource to urban students in being successful in learning mathematics. From the findings concerning resources, we discern two primary implications. The first implications centers on the question of what departments or programs can do to provide students opportunities to engage with others in terms of mathematics? Group work in coursework can lead to some interactions that extend outside of the classroom. A number of universities (e.g. University of Colorado, Boulder; University of California, Davis, etc.) have implemented educational practices such as structured group work, informal assessments, whole-class prompts that invite student contributions, and real-world tasks as part of their introductory science courses to invite more students into science majors. Informal spaces, participation in study groups, facilitated by faculty, have also been found to be helpful (Treisman, 1992). Writing and research groups that extend across advisors hold the potential for engaging in mathematics and emotional support while challenging an individualistic emphasis on mathematics learning. This practice would also provide multiple mentors to graduate students. These kind of social and content-related supports, based on participants' comments, are particularly important during the first years of the program, when students are adjusting to transitions from other universities and seek the guidance of others more knowledgeable about their specific graduate program and the community of mathematicians.

In this study, we have analyzed the comments of three female graduate students of mathematics in order to understand the potential of an identity framework to inform program and course design. This framework has focused our attention on aspects of the program culture and how competence is viewed by the participants. In addition, the framework takes seriously the valuations of the participants about different aspects of the program and the resources that have contributed to their success. We have discussed a number of implications related to the findings following from the analysis. These implications have to do with coursework tasks, professional development for faculty, and advising and peer support structures that might be implemented to enable and inspire students as they engage in doing mathematics at the graduate level.

We acknowledge that we analyzed the comments of three participants, and data reflecting the views of more graduate students are obviously needed in elaborating on and refining recommendations for mathematics programs. We can also see the potential for implications of our findings to other STEM graduate programs in which the culture and resources are critical in supporting and/or limiting students. The relatively recent work conducted to transform introductory science courses at the university level that we discussed earlier in this section show the promise of redesigning coursework with interaction and active learning in mind. The changes implemented have resulted in an increase in students' enrollment and performance academically in introductory science coursework (Perez-Pena, 2014). Analyzing the changes in such programs from the perspective of identity would provide information about how students make sense of the specific changes in coursework, program culture, and resources that students draw on.

Some may argue that the participants' experiences shared in this study are not necessarily confined only to women. We would agree that the perspective on the program culture and resources may be shared by other students, regardless of race, age, gender, or any other descriptors. We find it important to point out that the constellation of reasons supporting and delimiting women's participation in STEM fields and professions is complex, and the findings we have presented here provide possible situations that all students, including women and minorities, may experience. The questions guided by a focused lens on identity, paying particular attention to norms and valuations of program aspects, allow us to understand more deeply the perspectives of all students in an effort to make substantive changes in STEM education.

\section{References}

Bass, H. (2003). The Carnegie Initiative on the Doctorate: The case of mathematics. Notices of the American Mathematical Society, 50, 767-776. 
Boaler, J. (2002). Paying the Price for 'Sugar and Spice': Shifting the analytical lens in equity research. Mathematical Thinking and Learning, 4(2\&3), 127-144. https://doi.org/10.1207/S15327833MTL04023_3

Boaler, J., \& Greeno, J. G. (2000). Identity, agency, and knowing in mathematics worlds. Multiple Perspectives on Mathematics Teaching and Learning, 171-200.

Burton, L. (1999). The implications of a narrative approach to the learning of mathematics. Learning Mathematics: From Hierarchies to Networks, 21-35.

Cadinu, M., Maass, A., Rosabianca, A., \& Kiesner, J. (2005). Why do women underperform under stereotype threat? Evidence for the role of negative thinking. Psychological Science, 16(7), 572-578. https://doi.org/10.1111/j.0956-7976.2005.01577.x

Charney, R. (2014). President's report. American Association of Women in Mathematics Newsletter, 44(3), 1-2.

Cobb, P., \& Hodge, L. L. (2002). A relational perspective on issues of cultural diversity and equity as they play out in the mathematics classroom. Mathematical Thinking and Learning, 4(2-3), 249-284. https://doi.org/10.1207/S15327833MTL04023_7

Cobb, P., Gresalfi, M., \& Hodge, L. L. (2009). An interpretive scheme for analyzing the identities that students develop in mathematics classrooms. Journal for Research in Mathematics Education, 40-68.

Cohen, E. G., \& Lotan, R. A. (1995). Producing equal-status interaction in the heterogeneous classroom. American Educational Research Journal, 32(1), 99-120. https://doi.org/10.3102/00028312032001099

Dweck, C. S. (2008). Mindset: The new psychology of success. Random House Digital, Inc.

Eccles, J. S. (1987). Gender roles and women's achievement- related decisions. Psychology of Women Quarterly, 11, 135-172. https://doi.org/10.1111/j.1471-6402.1987.tb00781.x

Engle, R. A., \& Conant, F. R. (2002). Guiding principles for fostering productive disciplinary engagement: Explaining an emergent argument in a community of learners' classroom. Cognition and Instruction, 20(4), 399-483. https://doi.org/10.1207/S1532690XCI2004_1

Espinosa, L. (2011). Pipelines and pathways: Women of color in undergraduate STEM majors and the college experiences that contribute to persistence. Harvard Educational Review, 81(2), 209-241. https://doi.org/10.17763/haer.81.2.92315ww157656k3u

Fine, M., \& Weis, L. (1998). The unknown city: Lives of poor and working class young adults. Beacon Press.

Gee, J. P. (2000). Chapter 3: Identity as an analytic lens for research in education. Review of Research in Education, 25(1), 99-125. https://doi.org/10.3102/0091732X025001099

Gutstein, E. (2002). Roads towards equity in mathematics education: Helping students develop a sense of agency. In annual meeting of the American Educational Research Association, New Orleans.

Henrion, C. (1997). Women in mathematics: The addition of difference. Indiana University Press.

Herzig, A. H. (2002). Where have all the students gone? Participation of doctoral students in authentic mathematical activity as a necessary condition for persistence toward the PH. D. Educational Studies in Mathematics, 50(2), 177-212. https://doi.org/10.1023/A:1021126424414

Herzig, A. H. (2004). Becoming mathematicians: Women and students of color choosing and leaving doctoral mathematics. Review of Educational Research, 74(2), 171-214. https://doi.org/10.3102/00346543074002171

Hill, C., Corbett, C., \& St Rose, A. (2010). Why so few? Women in science, technology, engineering, and mathematics. American Association of University Women.

Holland, D. C., \& Eisenhart, M. A. (1990). Educated in romance: Women, achievement, and college culture. University of Chicago Press.

Johnson, L., Lee, A., \& Green, B. (2000). The PhD and the autonomous self: Gender, rationality and postgraduate pedagogy. Studies in Higher Education, 25(2), 135-147. https://doi.org/10.1080/713696141

Kellogg, A. P. (2001). A university beats the odds to produce black Ph. D.'s in math. The Chronicle of Higher Education.

Kurtz-Costes, B., Andrews Helmke, L., \& Ülkü-Steiner, B. (2006). Gender and doctoral studies: the perceptions of $\mathrm{Ph}$. D. students in an American university. Gender and Education, 18(2), 137-155. https://doi.org/10.1080/09540250500380513 
Lerman, S. (2000). The social turn in mathematics education research. Multiple Perspectives on Mathematics Teaching and Learning, 19-44.

Martin, D. B. (2000). Mathematics success and failure among African-American youth: The roles of sociohistorical context, community forces, school influence, and individual agency. Routledge.

McDermott, R., Goldman, S., \& Varenne, H. (2006). The cultural work of learning disabilities. Educational Researcher, 35(6), 12-17. https://doi.org/10.3102/0013189X035006012

Ong, M., Wright, C., Espinosa, L., \& Orfield, G. (2011). Inside the double bind: A synthesis of empirical research on undergraduate and graduate women of color in science, technology, engineering, and mathematics. Harvard Educational Review, 81(2), 172-209. https://doi.org/10.17763/haer.81.2.t022245n7x4752v2

Pena-Perez, R. (2014). Colleges reinvent introductory classes to keep more students in science. Retrieved from https://www.nytimes.com/2014/12/27/us/college-science-classes-failure-rates-soar-go-back-to-drawing-board.ht $\mathrm{ml}$ ?_r $=0$

Seymour, E., \& Hewitt, N. M. (1997). Talking about leaving: Why undergraduates leave the sciences. Boulder, CO: Westview Press.

Sfard, A., \& Prusak, A. (2005). Telling identities: In search of an analytic tool for investigating learning as a culturally shaped activity. Educational researcher, 34(4), 14-22. https://doi.org/10.3102/0013189X034004014

Strauss, A., \& Corbin, J. (1990). Basics of qualitative research (Vol. 15). Newbury Park, CA: Sage.

Treisman, U. (1992). Studying students studying calculus: A look at the lives of minority mathematics students in college. The College Mathematics Journal, 23(5), 362-372. https://doi.org/10.1080/07468342.1992.11973486

Walker, E. N. (2006). Urban high school students' academic communities and their effects on mathematics success. American Educational Research Journal, 43(1), 43-73. https://doi.org/10.3102/00028312043001043

Walkerdine, V. (1989). Femininity as performance. Oxford Review of Education, 15(3), 267-279. https://doi.org/10.1080/0305498890150307

Wilson, R. (2003). Strength in Numbers. The Chronicle of Higher Education, 49(45), 10-12.

Wilson, Z. S., Holmes, L., Sylvain, M. R., Batiste, L., Johnson, M., McGuire, S. Y., \& Warner, I. M. (2012). Hierarchical mentoring: A transformative strategy for improving diversity and retention in undergraduate STEM disciplines. Journal of Science Education and Technology, 21(1), 148-156. https://doi.org/10.1007/s10956-011-9292-5 